\title{
Juvenile Spondyloarthritis
}

National Cancer Institute

\section{Source}

National Cancer Institute. Juvenile Spondyloarthritis. NCI Thesaurus. Code C114347.

A group of chronic, inflammatory childhood diseases characterized by arthritis and enthesitis. This disorder can affect the axial skeleton in late childhood or young adulthood. 